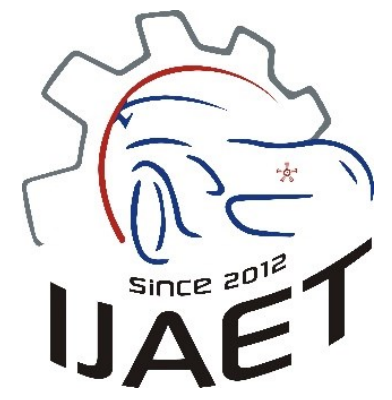

e-ISSN: 2146 - 9067

International Journal of Automotive

Engineering and Technologies

journal homepage:

https://dergipark.org.tr/en/pub/ijaet

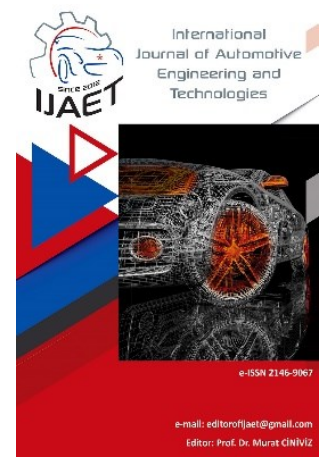

Original Research Article

\title{
Topology optimization of clutch drive plate for commercial vehicles
}

\author{
Özgür Erdoğan ${ }^{1, *}$ \\ $1,{ }^{*}$ Valeo Automotive Systems, Bursa - Turkey
}

\section{ARTICLE INFO}

1. 0000-0001-6936-9808

Doi: $10.18245 /$ ijaet.821855

* Corresponding author ozgur341@gmail.com

Received: Nov 20, 2020

Accepted: Jan 29, 2021

Published: Mar 31, 2021

Published by Editorial Board Members of IJAET

(C) This article is distributed by Turk Journal Park System under the CC 4.0 terms and conditions.

\begin{abstract}
The drive plate is one of the main components of the clutch disc which transmits the torque from engine to transmission. For commercial vehicle applications, the drive plate works under immense torsional forces thanks to high engine torque values. Therefore, high durability is expected during the operational life of the clutch disc drive plate. On the other hand, the lightweight of the vehicle components has an important role in $\mathrm{CO}_{2}$ emission standards. To be able to assure this regulation, companies conduct studies for decreasing the vehicle mass. In this study, the drive plate's 3D CAD data is created based on the current design by using CATIA solid creation software. Finite Element Analysis (FEA) was carried out in a statical analysis tool and to be verified for real-life working conditions. The topology optimization was performed using CAE software (ANSYS) in order to reduce the weight of the drive plate without compromising on mechanical durability. The optimized design was proposed based on topology optimization outputs. The strength of the proposed design was investigated by using FEA analysis and results are compared to the acceptance criteria of the material. The optimized geometry is equally durable and lighter in weight compared to the existing model. Mass was decreased \%18 without compromising mechanical durability.

Keywords: Clutch, Disc, Drive plate, Topology optimization, Finite element analysis
\end{abstract}

\section{Introduction}

Clutch is an important component for the powertrain system in a passenger car, mediumduty and heavy-duty vehicles. The clutch system is the set of mechanical elements allowing to smoothly make and break the connection between the engine and the driveline(Dolcini et al.,2010, p.13). Pressure plate cover assembly (PPCA), disc and release bearing are the components of the clutch system (Figure 1).

There are two basic disc designs in clutch systems: rigid and dampened. Rigid discs are steel plates to which friction linings, or facings, are bonded or riveted. Dampened discs have coaxial dampening springs incorporated into the disc hub (Bennett, 2018, p.434). The Clutch disc works between the flywheel and pressure plate. When the driver presses the clutch pedal during gear shifting, the pressure plate moves and a gap occurs between the disc and pressure plate; therefore, the driver can change the gear. Conversely, when the driver releases the clutch pedal after shifting, the disc is clamped between 
the pressure plate and flywheel. Hence, torquetransmitting starts throughout friction facing to the input shaft. The drive plate is located between friction facings and disc hub and it is a critical element in torque transmission. Torque flows from friction material to drive plate and then from drive plate to hub. Clutch disc components are shown in figure 2 .

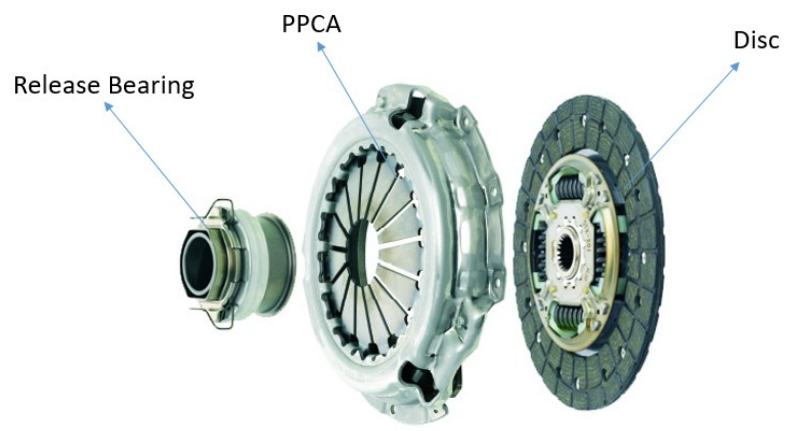

Figure 1. PPCA, disc and release bearing

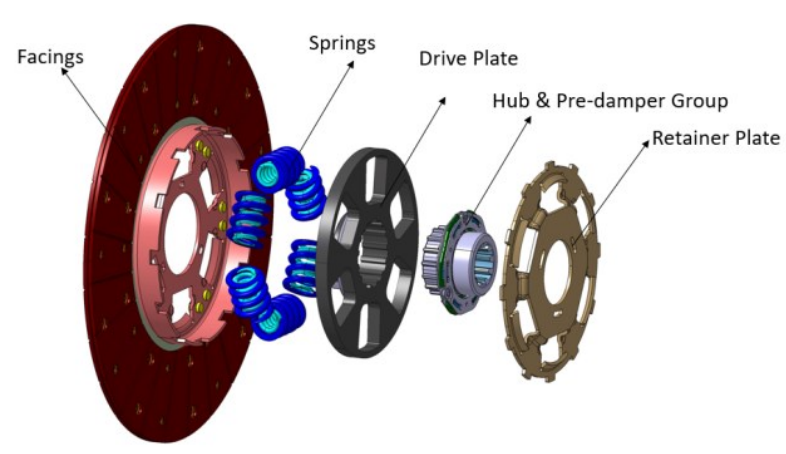

Figure 2. Clutch disc components

The drive plate is subjected to higher torque values for commercial vehicles compared to passenger cars. During different working conditions such as construction and haulage, peak torque values arise and these torque values lead to instant high-stress points on the drive plate. Therefore, validation of drive plate design is a critical step during the clutch development process. On the other hand, the lightweight of the vehicle components has a vital role in terms of $\mathrm{CO}_{2}$ emission standards. To be able to assure this regulation, companies conduct studies for decreasing the vehicle mass.

In the literature, there are some studies including optimization for clutches. Kaya (2006) performed shape optimization of a clutch diaphragm spring using with genetic algorithm. Kaya et al. (2010) performed topology and shape optimization for failed clutch fork design. A simulation model was correlated with field data. After that, the novel design was proposed by using topology and shape optimization methods. The $\% 24$ mass reduction was obtained and rigidity improved by $\% 37$ compared to the original design. Guanghui (2012) conducted a study about clutch disc components. Modal analysis of waveform (metallic disc), clamping plate (drive plate), hub was analyzed. Natural frequency is investigated. As a second step, topology optimization was done for the metallic disc. As a result, the stress distribution is done homogeneously. Cury and Baruffaldi (2012) bring out a practical approach to fork design. Manufacturing and functional constraints are taken into account. Stiffness and volume change was declared. Further study steps were proposed. Ozansoy et al. (2015) investigated the optimum design of clutch systems and in this study, simulation for clutch engagement system was done and new proposals were shared with product designers and developers. Kaya et al. (2015) studied clutch cushion disc shape optimization and investigated optimum cushion disc dimensions that provide the target stiffness curve by using the differential evolution algorithm. Two different case studies were studied as an optimization problem. Afterward, Pascal software code was developed to solve the optimization problem. A new method was proposed to shorten the design period of the clutch cushion disc. Dogan et al. (2015) investigated the stress distribution of the tractor clutch finger. Topology and shape optimization was conducted. As a result of their study, a new tractor clutch finger design was proposed with better durability and deformation performance. Zheng and Gong (2019) investigated dry clutch pressure plate thermo-mechanical behavior by using numerical simulation and topology optimization methods. Engagement and disengagement movement is simulated based on real working conditions. Temperature change and thermal deformation results were obtained. These results were used as input for topology optimization. Finally, the improved design is validated and mass was reduced by $3.1 \mathrm{~kg}$. Yuvaraja et al. (2019) searched the design and development of the clutch fork system by using the topology optimization method. They focused on topology optimization in order to obtain mass reduction without compromising functional performance. Stress distribution and total deformation values are compared with different materials: cast iron and polypropylene. 
Waghmare et al. (2020) conducted a study regarding the modal analysis of clutch fork for serial design and optimized design. Topology optimization is done to reduce the material of the clutch fork. Modal analysis results were comparatively investigated of the base fork and optimized fork. The study reveals that there is no significant change in deformation and the natural frequency of the optimized clutch fork. In this study, Ansys finite element software was used in order to define the current status of design and over-torque simulation was performed based on serial working conditions. Topology optimization was performed to determine new design areas for lightweight. Different emptying geometries were applied to the drive plate and results were compared in terms of stress on critical locations and mass reduction. Mass was decreased \%18 without compromising mechanical durability.

\section{Material and Method}

\subsection{Finite element analysis}

The first step of the finite element analysis is CAD data creation. Thus, the $3 \mathrm{D}$ solid model was created with CATIA design software (figure 3). Even though the part is symmetrical, complete geometry was used due to the topology optimization step. Necessary surfaces for load application were created on the geometry.

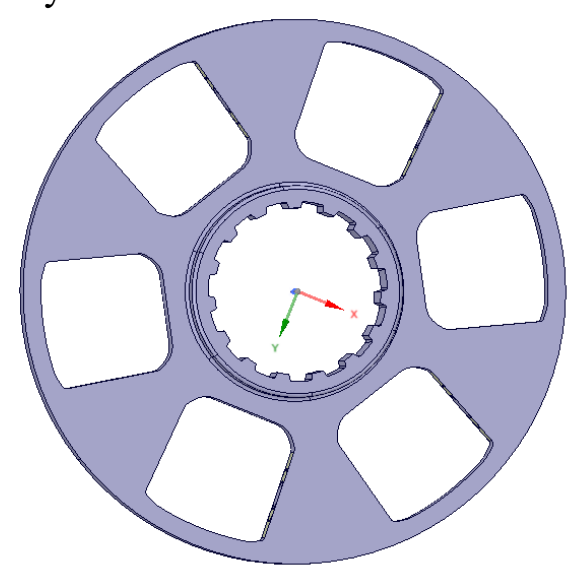

Figure 3. Solid model of the drive plate

The drive plate is made of $42 \mathrm{CrMo} 4$ alloy steel and mechanical properties are given in Table 1 according to Valeo internal material datasheet. After creating the CAD model of the drive plate, geometry was imported to Ansys simulation software for the creation of a finite element model. Statical structural analysis was applied in the workbench module. In the mesh model, tetrahedral elements were used due to the complex geometry of the drive plate. The mesh model is consists of 62000 elements and 100000 nodes. Additionally, the face sizing method was applied for the spline region with $3 \mathrm{~mm}$ sizing. The mesh model of the drive plate is shown in figure 4.

Table 1 Mechanical Properties of 42CrMo4

\begin{tabular}{ll}
\hline Property & Value \\
\hline Modulus of Elasticity & $200 \mathrm{GPa}$ \\
Yield Strength & $450 \mathrm{MPa}$ \\
Tensile Strength & $655 \mathrm{MPa}$ \\
Poison's Ratio & 0.3 \\
\hline
\end{tabular}

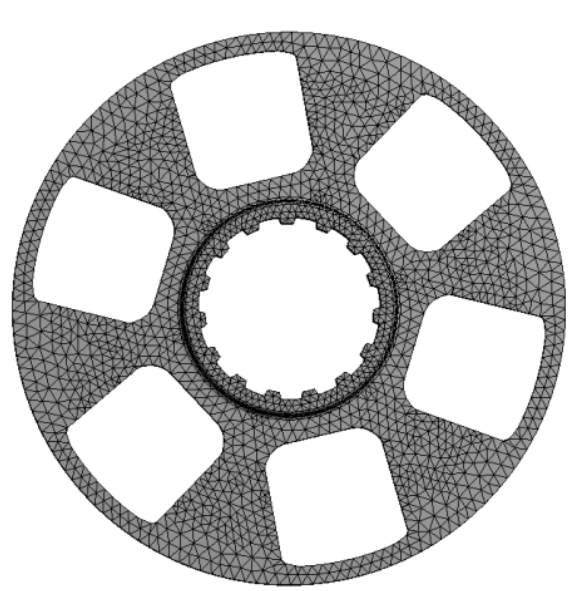

Figure 4. Mesh model of the drive plate

Loads and boundary conditions which were applied on the drive plate were defined in Ansys. Maximum engine torque value was multiplied by 2.5 as a safety factor and divided to distance from the input shaft to spring contact area and force value obtained. This force value is divided into the spring contact area. As a result of this calculation, four different pressure was applied. These pressure values were both applied as drive and coast directions. Pressure values are given in table 2 .

Table 2 Applied Pressure Loads

\begin{tabular}{cc}
\hline Load & Value \\
\hline External spring upper section pressure & $52 \mathrm{MPa}$ \\
External spring inner section pressure & $56 \mathrm{MPa}$ \\
Internal spring upper section pressure & $14 \mathrm{MPa}$ \\
Internal spring inner section pressure & $15 \mathrm{MPa}$ \\
\hline
\end{tabular}

Three different displacements were defined as geometry based on real working conditions. Displacement 1 was defined to right-sided surfaces of the spline teeth. Displacement 2 was defined as left-sided surfaces of the spline teeth. Moreover, displacement 3 was defined to the upper surface of the clutch disc hub. All loads and boundary conditions were shown in figure 5 . 


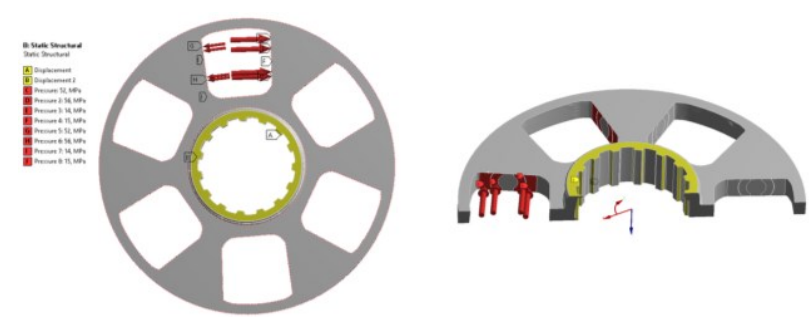

Figure 5. Loads and Boundary Conditions

To decide whether drive plate geometry is acceptable or not, maximum principal stress was investigated. FEA results revealed locations of high stresses and all stress distribution throughout the drive plate. Based on the overtorque test results, part breakage location is the bottom corner of the window fillet of the drive plate. Therefore, this area of the part was taken into account for stress evaluation. The highest maximum principal stress value occurred at the window bottom corner area, whose value is 545 $\mathrm{MPa}$. The maximum stress location was shown in figure 6.

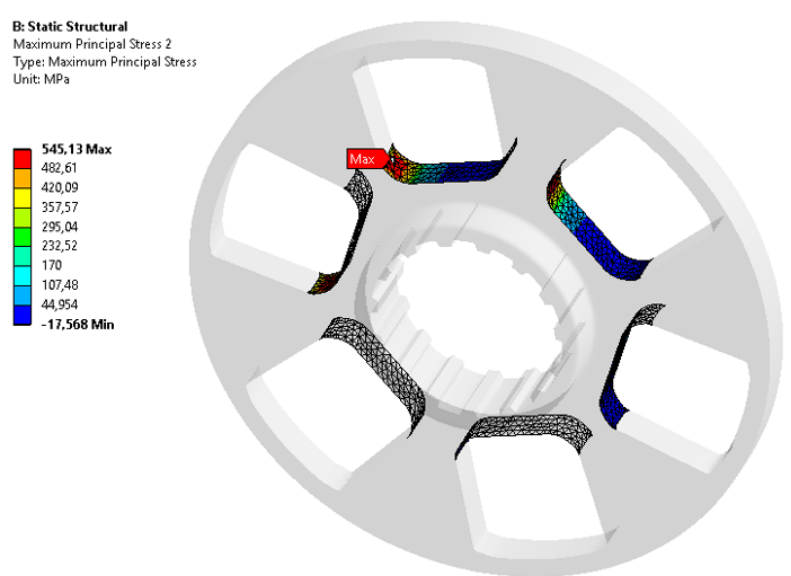

Figure 6. Maximum Stress Location

\subsection{Topology optimization}

Optimization is everywhere, from airline scheduling to finance and from the Internet routing to engineering design. Optimization is an important paradigm itself with a wide range of applications. In almost all applications in engineering and industry, we are always trying to optimize something - whether to minimize the cost and energy consumption or to maximize the profit, output, performance and efficiency. In reality, resources, time and money are always limited; consequently, optimization is far more important in practice (Koziel and Yang,2011). Structural optimization methods are used to create optimum design considering different variables (mass, volume, strength, cost etc.). The aim of structural optimization techniques is to generate ideal concepts. The advantage of these techniques is to minimize the loss of cost and time. Structural optimization methods are divided into two groups which are shape and topology optimization.

Topology optimization allows the maximum freedom in the design space by a possible change of geometry. Design space, boundary conditions and loads are necessary data in order to perform topology optimization. With the results of topology optimization, a detailed design of the part can be done. In this study, the design space was defined according to the dimensions of the clutch disc drive plate. The design and non - design regions were defined and shown in figure 7 .

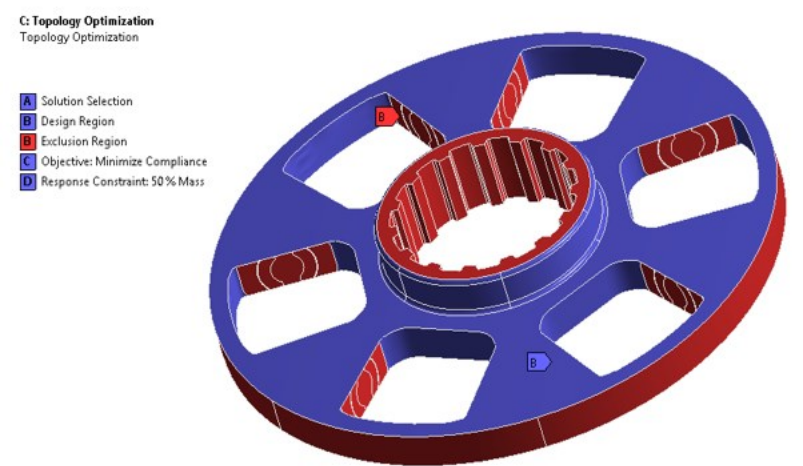

Figure 7. Design Regions and Exclusion Regions

Drive plate spline area and springs contact area were defined as the exclusion region. Rest surfaces were defined as the design region. $\% 50$ mass decrease was defined for topology optimization. As an objective, minimization of compliance was defined. The maximum iteration limit was defined as 100 .

\section{Results and Discussion}

The topology optimization result was shown in figure 8. A consequence of topology optimization with potential mass decrease may be from $2264 \mathrm{~g}$ to $1294 \mathrm{~g}$.

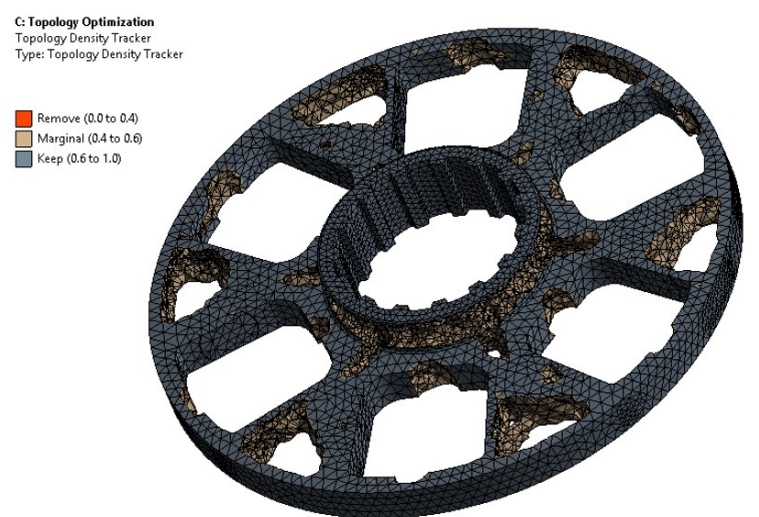

Figure 8. Topology Optimization Result 
Thanks to the topology optimization result, a new geometry design was done. Also, manufacturability was taken into account during the new design. The proposed new drive plate design with emptying holes as shown in figure 9.

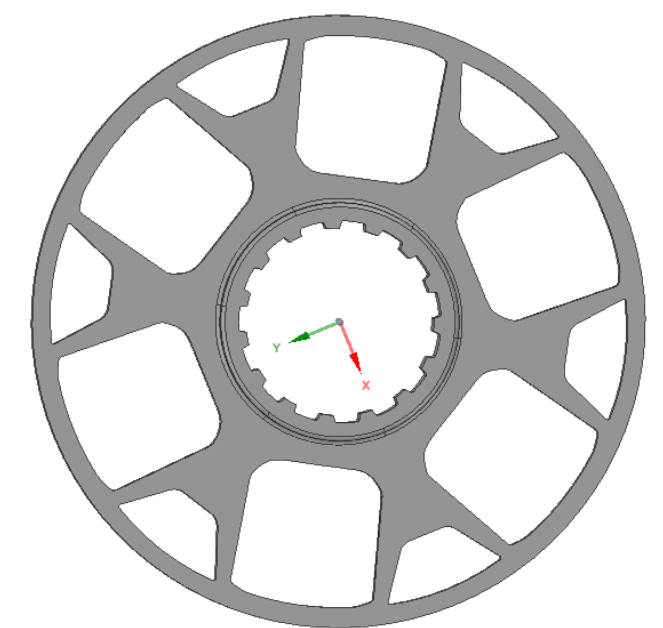

Figure 9. Proposed New Design of the Drive Plate

After the new drive plate design according to topology optimization results, geometry should be verified with static structural finite element analysis. Hence, FEA was conducted. The same mesh type and size, loading and boundary conditions were applied to the new drive plate CAD model and results were gained. The static structural analysis results reveal that the maximum principal stresses are increased to 549 MPa (Figure 10).

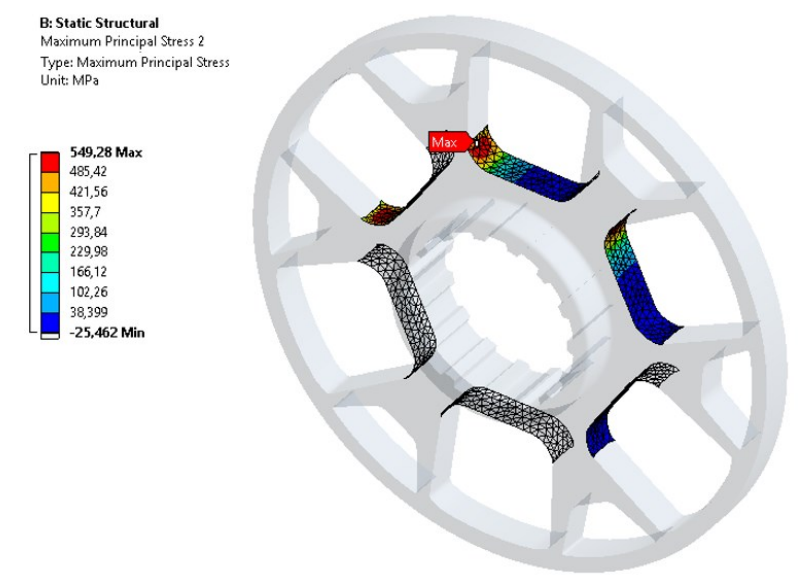

Figure 10.Maximum Stress Location for Optimized Geometry

Comparison of the finite element analysis results of the initial design and the modified design of the heavy-duty clutch disc drive plate is shown in table 3.

From the comparison table, it can be seen that after modifying the topology of the clutch disc drive plate, the maximum principal stresses and total deformation are increased. Although this increases, the stress level is within the permissible limits. Thus, the purpose of the topology optimization serves.

Table 3 Result Comparison

\begin{tabular}{cccc}
\hline & $\begin{array}{c}\text { Initial } \\
\text { Design }\end{array}$ & $\begin{array}{c}\text { Modified } \\
\text { Design }\end{array}$ & $\begin{array}{c}\text { Change } \\
(\%)\end{array}$ \\
\hline $\begin{array}{c}\text { Maximum } \\
\text { Principle Stress }\end{array}$ & 545 & 549 & +0.7 \\
(MPa) & & & \\
Mass (g) & 2264 & 1845 & -18 \\
Total Deformation & 0.25 & 0.29 & +16 \\
\hline
\end{tabular}

From the comparison table, it can be seen that after modifying the topology of the clutch disc drive plate, the maximum principal stresses and total deformation are increased. Although this increases, the stress level is within the permissible limits. Thus, the purpose of the topology optimization serves.

Greenhouse gas emission regulations force vehicle manufacturers to decrease $\mathrm{CO}_{2}$ values. Therefore, companies put effort into reducing vehicle mass. Powertrain components are one of the significant lightweight areas of vehicles. As a consequence of this study, the \%18 mass reduction was achieved. So that, a positive contribution to this lightweight target was made. Additionally, due to less material usage, component cost is decreased as well.

In further studies, prototype production will be done with the proposed lighter geometry by using the wire erosion method. Validation bench tests will be done according to real working conditions in order to the correlation of the FEA results.

\section{Conclusion}

Topology optimization is an excellent tool for lightweight by means of mass reduction while maintaining functionality. Additionally, shortening design validation durations has vast importance in the automotive industry due to highly competitive market conditions. In this paper, apart from previous studies, the clutch disc drive plate for heavy-duty applications is analyzed for the over-torque condition using finite element software (ANSYS) and stresses and deformation are obtained. The topology optimization of the component is carried out to find the optimum material distribution and a substantial reduction in weight about $419 \mathrm{~g}$ is obtained and also obtained stress and deformation within acceptance criteria. 


\section{References}

1. Dolcini, P.J., Wit, C.C., Bechart, H., "Dry clutch control for automotive applications", Advances in Industrial Control, Springer, 2010.

2. Bennett, S., "Heavy duty truck systems - 7th edition", Cengage, 2018.

3. Kaya, N., "Optimal design of an automotive diaphragm spring with high fatigue resistance", International Journal of Vehicle Design, 40 (1-3), pp.126-143, 2006.

4. Kaya, N., Karen, İ. and Öztürk, F., "Redesign of a failed clutch fork using topology and shape optimization by the response surface method", Materials and Design, 31, pp. 3008 3014, 2010.

5. Guanghui, Z., "The research on modal analysis and topology optimization in car clutch parts", Applied Mechanics and Materials,189, pp. 486-490, 2012.

6. Cury, R. C., "Topological optimization of clutch fork using finite element analyses", SAE Technical Paper Series, 2012.

7. Ozansoy, O., Tevruz, T. and Mugan A., " Multiobjective pareto optimal design of a clutch system", International Journal of Engineering Technologies, Vol.1, No.1-2015, pp.25-43, 2015.

8. Kaya, N., Kartal, S., Çakmak, T., Karpat, F. and Karaduman A., "Shape optimization of clutch cushion disc using differential evolution method", Proceedings of the ASME International Mechanical Engineering Congress \& Exposition, 2015 Nov 13-19, Houston, Texas, USA, 2015.

9. Dogan, O., Karpat, F., Kaya, N., Yuce, C., Genc, M.O. and Yavuz, N., "Optimum design of tractor clutch PTO finger by using topology and shape optimization", Proceedings of the ASME International Mechanical Engineering Congress \& Exposition Houston, Texas, USA, 2015.

10. Zheng, X., and Gong, Y., "Numerical simulation and topological optimization of the dry clutch pressure plate", Journal of Physics: Conference Series, 2019.

11. Yuvaraja, S., Arunkumar, G., Sai, B.V. and Dhinakaran, P.R.V., "Design and development of a compliant clutch fork using topology optimization", International Journal of
Innovative Technology and Exploring Engineering, Vol. 8, - Issue 11, 2019.

12. Waghmare, K.U., Kshirsagar, B.D. and Bhangale, R. S., "Modal analysis of original and optimized clutch fork using ANSYS workbench", International Research Journal of Engineering and Technology, Vol. 7, Issue 08, 2020.

13. Koziel, S. and Yang, X. S., "Computational Optimization, Methods and Algorithms", Springer, 2011.

14. Valeo Automotive Material Datasheet, 2020. 